\title{
Study of the controlled chain-growth polymerization of poly(3,6-phenanthrene)
}

\section{Michiel Verswyvel, ${ }^{a}$ Charly Hoebers, ${ }^{a}$ Julien De Winter, ${ }^{b}$ Pascal Gerbaux ${ }^{b}$ and Guy Koeckelberghs ${ }^{a}$}

${ }^{\text {a }}$ Laboratory for Polymer Synthesis, Group of Polymer Chemistry \& Materials, KU Leuven, Celestijnenlaan 200F, B-3001 Heverlee (Leuven), Belgium

${ }^{\mathrm{b}}$ Mass Spectrometry Research Group, Interdisciplinary Center for Mass Spectrometry, University of Mons-UMONS, 23 Place du Parc, B-7000 Mons, Belgium

Correspondence to: Guy Koeckelberghs (E-mail: guy.koeckelberghs@chem.kuleuven.be)

Additional Supporting Information may be found in the online version of this article.

\section{ABSTRACT}

This manuscript investigates the possibilities to obtain helical conjugated polymers following a controlled chain-growth polymerization mechanism with external initiation. Attempts to prepare poly(3,6-(9,10-di(octyloxy))phenantrene)s using the existing chain-growth mechanisms using existing Kumada or Negishi couplings were unsuccessful because the difficulty to quantitatively prepare the GRIM reagent starting from the envisaged precursor, namely 3,6-dibromo-(9,10-

di(octyloxy))phenantrene. On the other hand, a Suzuki-Miyaura coupling polymerization using $\mathrm{Pd}\left(\mathrm{P}^{\mathrm{t}} \mathrm{Bu}_{3}\right)$ as the catalyst clearly allows the polymerization to proceed. The reaction conditions were optimized and an in-depth study with GPC and MALDI-ToF of the underlying mechanisms was performed. Nevertheless, a prolonged chain-growth mechanism was not achieved for the targeted polymers.

KEYWORDS: Poly(di(octyloxy)phenanthrene), chain-growth polymerization, Suzuki-Miyaura, external initiator

\section{INTRODUCTION}

Acquiring control on the synthesis of the different classes of $\pi$-conjugated polymers (CPs) is one of the main goals polymer chemists pursue nowadays. CPs are used because of their promising applications in electronic devices, e.g. organic solar cells, organic LED's, supercapacitors, biosensors, etc. Their molecular architecture and structure are playing a dominant role in their performance. ${ }^{1,2}$ Building predetermined molecular structures with low $\oslash$ values was the challenge in the past and will continue to be so in the future. The major breakthrough was the discovery of the Kumada catalyst-transfer polymerization of poly(3-alkylthiophene) with $\mathrm{Ni}(\mathrm{dppp}) \mathrm{Cl}_{2}$ as a catalyst by the research groups of Yokozawa and McCullough in $2004 .{ }^{3-6}$ A controlled chain-growth polymerization mechanism was demonstrated. Shortly after, also other CPs were polymerized in a chain growth manner using the same or other catalysts: poly(thiophenes) with $\left.\mathrm{Pd}(\mathrm{Ruphos}),{ }^{7,8} \mathrm{Pd}\left({ }^{\mathrm{t}} \mathrm{Bu}\right)_{3}\right),{ }^{9} \mathrm{Ni}(\alpha \text {-diimine })^{10,11}$ or $\mathrm{Pd}(\mathrm{NHC}),{ }^{12}$ poly(fluorenes) with $\mathrm{Ni}(\mathrm{acac}) / \mathrm{dppp},{ }^{13} \mathrm{Pd}\left(\mathrm{P}^{\mathrm{t}} \mathrm{Bu}_{3}\right),{ }^{14} \mathrm{Pd}(\text { Ruphos })^{7}$ or $\mathrm{Pd}(\mathrm{NHC}),{ }^{12}$ poly $(p$-phenylene) with $\mathrm{Pd}\left(\mathrm{P}^{\mathrm{t}} \mathrm{Bu}_{3}\right),{ }^{15} \mathrm{Ni}(\mathrm{dppe}),{ }^{16,17}$ or $\mathrm{Pd}(\mathrm{NHC}){ }^{12}$ poly $\left(p\right.$-phenylene ethynylene) with $\mathrm{Pd}\left(\mathrm{P}^{\mathrm{t}} \mathrm{Bu}_{3}\right),{ }^{18}$ poly(pyrrole) with $\mathrm{Ni}(\mathrm{dppe}),{ }^{19}$ etc $((\mathrm{NHC})=\mathrm{N}$-heterocyclic carbene, $(\mathrm{dppp})=$ diphenylphosphinopropane, $(\mathrm{dppe})=$ diphenylphosphinoethane). Initiation of these polymers can happen in two ways. The catalyst salt can be added and, after an initial reduction, the initiating moiety is formed in situ. Alternatively, or a premade external initiator can be used. The latter approach allows the incorporation of functional end

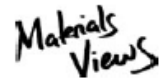


groups and is well demonstrated for poly(3-alkylthiophene)s by the groups of Kiriy, Luscombe, Verduzco and our research group. ${ }^{20-23}$ External initiation allows to attach the polymers to nanoparticles ${ }^{24}$ or to each other using click-chemistry. ${ }^{23,25}$

The synthetic exploration of the CPs led to endearing primary and secondary structures. Besides the linear homo- and random- or block-copolymers, also star-shaped and branched CPs have been reported. ${ }^{26-41}$ Extensive researches on the helical structure of polymers also made its way into the field of the CPs to be used as mimics for complex natural systems, chirally aligned chromophores or chiral sensing. A plethora of CPs such as functionalized poly(acetylene)s, ${ }^{42}$ poly $\left(m\right.$-phenylene ethynylene) $s,{ }^{43-45}$ poly(thiophene)s, ${ }^{46}$ poly(dithienopyrrole) $s^{47}$ and others were designed to adopt a helical conformation induced by additives, solvophobic effects, hydrogen bonds and more. ${ }^{48-53}$ Notwithstanding the amount of helical polymers synthesized using controlled chain-growth conditions, none has already been made applying an external initiator. Therefore, the ability to equip the resulting polymers with functional end groups remains unexplored.

It was chosen to investigate poly(3,6-dioctylphenanthrene)s (3,6-PPhs) since these polymers have not yet been polymerized in a chain-growth fashion before and adopt a helical conformation induced by solvophobic effects. ${ }^{54}$ Even more, they exhibit several advantages as blue emitter ${ }^{55}$ over other conventional blue emitters such as poly( $p$-phenylene $)^{56-58}$ and poly(fluorene). ${ }^{59-61}$ So far, 3,6-PPhs were synthesized using a Suzuki step-growth mechanism with $A_{2}$ - and $B_{2}$-monomers, resulting in low control on the polymerization. ${ }^{54}$ This manuscript aims to convert the synthesis of 3,6-PPhs into a catalysttransfer polymerization using $\mathrm{Ni}$ - and $\mathrm{Pd}$-based mechanisms with an external initiator.

\section{EXPERIMENTAL}

\section{Reagents and instrumentation}

All reagents were purchased from Sigma-Aldrich, Acros Organics, Merck or Alfa Aesar. Reagent grade solvents were dried by a solvent purification system MBRAUN SPS 800 (columns with activated alumina). Gel Permeation Chromatography (GPC) measurements were done with a Shimadzu 10A apparatus with a tunable absorbance detector and a differential refractometer in THF as eluent toward polystyrene standards. Electron lonization Mass spectra (EI-MS) were recorded using an Agilent HP5989, whereas MALDI-ToF experiments were conducted using a Waters QToF Premier mass spectrometer. ${ }^{62}{ }^{1} \mathrm{H}$ and ${ }^{13} \mathrm{C}$ nuclear magnetic resonance (NMR) measurements were carried out with a Bruker Avance $300 \mathrm{MHz}$. 3,6dibromo-9,10-di(octyloxy)phenanthrene 1 was prepared as described in the literature. ${ }^{63,64}$

\section{Synthesis of monomer 3}

KOAc $(5.07 \mathrm{~g}, 51.7 \mathrm{mmol})$ and $\mathrm{Pd}(\mathrm{DPPF}) \mathrm{Cl}_{2} \quad(456 \mathrm{mg}, 559 \mu \mathrm{mol})$ were added to a solution of 1 (4.87 $\mathrm{g}$, $8.22 \mathrm{mmol})$ in dry 1,4-dioxane $\quad(30 \mathrm{~mL})$. The reaction mixture was purged with argon and an argon purged solution of bis(pinacolato)diboron $(2.09 \mathrm{~g}, 8.22 \mathrm{mmol})$ in dry 1,4-dioxane was added. The solution was stirred for $1 \mathrm{~h}$ at $80{ }^{\circ} \mathrm{C}$. Subsequently, the solution was concentrated under reduced pressure and the crude mixture was purified with column chromatography $\left(\mathrm{SiO}_{2}, \mathrm{CH}_{2} \mathrm{Cl}_{2} /\right.$ heptane 1/1) to yield a pale yellow oil (1.91 $\mathrm{g}, 36 \%)$.

${ }^{1} \mathrm{H}$ NMR (300 Mhz, CDCl 3 , $): 9.00(\mathrm{~s}, 1 \mathrm{H}, \operatorname{Ar~H}), 8.90(\mathrm{~s}, 1 \mathrm{H}, \operatorname{Ar~H}), 8.21(\mathrm{~d}, \mathrm{~J}=8.2 \mathrm{~Hz}, 1 \mathrm{H}, \operatorname{Ar~H}), 8.10(\mathrm{~d}, \mathrm{~J}=$ $8.8 \mathrm{~Hz}, 1 \mathrm{H}, \mathrm{Ar} \mathrm{H}), 8.02(\mathrm{~d}, \mathrm{~J}=8.2 \mathrm{~Hz}, 1 \mathrm{H}, \operatorname{Ar~H}), 7.68(\mathrm{~d}, \mathrm{~J}=8.8 \mathrm{~Hz}, 1 \mathrm{H}, \mathrm{Ar} \mathrm{H}), 4.19\left(\mathrm{~m}, 4 \mathrm{H}, \mathrm{CH}_{2}\right), 1.96-1.82$ $\left(\mathrm{m}, 4 \mathrm{H}, \mathrm{CH}_{2}\right), 1.61-1.48\left(\mathrm{~m}, 4 \mathrm{H}, \mathrm{CH}_{2}\right), 1.43\left(\mathrm{~s}, 12 \mathrm{H}, \mathrm{CH}_{3}\right), 1.40-1.23\left(\mathrm{~m}, 16 \mathrm{H}, \mathrm{CH}_{2}\right), 0.90\left(\mathrm{t}, 6 \mathrm{H}, \mathrm{CH}_{3}\right) ;{ }^{13} \mathrm{C}$ NMR (75 Mhz, $\left.\mathrm{CDCl}_{3}, \delta\right): 144.0,143.3,132.7,132.1,130.4,130.0,129.8,128.2,126.8,125.6,124.1$, 
121.4, 120.3, 84.0, 73.7, 73.6, 31.8, 30.5, 30.4, 29.5, 29.3, 26.3, 26.2, 24.9, 22.7, 14.1; El-MS $(\mathrm{m} / \mathrm{z}(\%))=$ $637\left[\mathrm{M}^{\bullet+}\left({ }^{10} \mathrm{~B} /{ }^{79} \mathrm{Br}\right)\right], 413\left[\mathrm{M}^{\bullet+}\left({ }^{10} \mathrm{~B} /{ }^{79} \mathrm{Br}\right)-\mathrm{C}_{16} \mathrm{H}_{32}\right]$

\section{Ring walking experiment}

Compound 1 (59.2 mg, $0.100 \mathrm{mmol})$ and phenyl boronic acid pinacol 5 (20.4 mg, $0.100 \mathrm{mmol}$ ) were loaded into a $25 \mathrm{~mL}$ flask, schlenked with argon and dissolved in $4.1 \mathrm{~mL}$ THF. Next, $\mathrm{Pd}\left(\mathrm{P}^{\mathrm{t}} \mathrm{Bu}_{3}\right)_{2}(5 \mathrm{~mol} \%$, $2.5 \mathrm{mg}, 5.00 \mu \mathrm{mol})$ was weighted in a test tube, schlenked with argon and cannulated with $2 \mathrm{~mL}$ THF to the $25 \mathrm{~mL}$ flask. Subsequently, $\mathrm{K}_{2} \mathrm{CO}_{3}(110 \mathrm{mg}$, $\quad 0.796 \mathrm{mmol})$ in $\mathrm{H}_{2} \mathrm{O}(0.2 \mathrm{~mL})$ was added to the solution and the reaction mixture was allowed to stir overnight. Thereafter, the crude mixture was washed with brine and dried with $\mathrm{MgSO}_{4}$. Finally, the solvent was evaporated under vacuum and the crude mixture was analyzed with ${ }^{1} \mathrm{H}$ NMR en mass spectrometry.

\section{Suzuki-Miyaura coupling polymerization}

The monomer 3 (158 mg, $0.246 \mathrm{mmol}$ ) and poly(styrene) $\left(\overline{M_{p}}=316500 \mathrm{~g} / \mathrm{mol}, \mathrm{Ð}=1.02,25 \mathrm{mg}\right)$ as an internal standard were loaded in a round-bottomed flask dissolved in dry THF ( $8.5 \mathrm{~mL})$. Subsequently, a solution of $\mathrm{K}_{2} \mathrm{CO}_{3}(276 \mathrm{mg}, 2.00 \mathrm{mmol})$ in distilled $\mathrm{H}_{2} \mathrm{O}(0.5 \mathrm{~mL})$ was added and the atmosphere in the flask was replaced with argon. Next, a solution of ${ }^{\mathrm{t}} \mathrm{Bu} \mathrm{u}_{3} \mathrm{PPd}(\mathrm{Ph}) \mathrm{Br} 4(5.74 \mathrm{mg}, 12.3 \mu \mathrm{mol})$ in dry THF (1 mL) and purged with argon was added and the reaction mixture was stirred overnight at room temperature. Aliquots $(0.5 \mathrm{~mL})$ were taken at predetermined times and terminated in acidified $\mathrm{THF}(\mathrm{HCl}, 2 \mathrm{M})$ solution.

\section{RESULTS AND DISCUSSION}

Chain-growth polymerization mechanisms for several CPs were frequently demonstrated in the literature. The successful mechanisms are (Scheme 1): (i) Kumada coupling polymerizations (ii) Negishi coupling polymerizations and (iii) Suzuki-Miyuara coupling polymerizations.

Amongst these three well-known polymerization procedures, both mechanisms (i) and (ii) are based on the Grignard metathesis (GRIM) reaction as far as the monomer formation is concerned.

\section{GRIM-based mechanisms}

\section{Monomer synthesis}

The synthesis of the precursor monomer used in the Kumada and Negishi mechanisms, 3,6-dibromo9,10-di(octyloxy)phenanthrene 1, was performed as described before. ${ }^{64}$ Of course, the actual monomer formation is the in situ conversion of the precursor monomer to the 3-bromo-6-bromomagnesio derivative 2 using a Grignard metathesis (GRIM) reaction. Treatment of 1 with 1 equivalent of 'PrMgCl.LiCl in dry THF $(0.1 \mathrm{M})$ results in reproducible low yields in monomer, even if higher temperatures or longer reaction times are selected (Table 1). As a consequence, further polymerization is unlikely to properly proceed following the Kumada and Negishi mechanisms. Therefore, we decided to focus on the alternative $\mathrm{Pd}\left(\mathrm{P}^{\mathrm{t}} \mathrm{Bu} \mathrm{u}_{3}\right)$ mechanism.

\section{$\mathrm{Pd}\left(\mathrm{P}^{\mathrm{t}} \mathrm{Bu} \mathrm{u}_{3}\right)$ mechanism}

\section{Monomer synthesis}

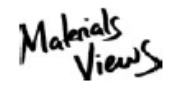


Treatment of 1 with $\mathrm{KOAc}, \mathrm{Pd}(\mathrm{DPPF}) \mathrm{Cl}_{2}$ and bis(pinacolato)diboron in dry 1,4-dioxane resulted in 3 as depicted in Scheme 2.

\section{Synthesis of the external initiator}

We opted to use the common phenyl initiator 4 instead of a functionalized derivative (Scheme 3), as the aim is to develop and prove the chain-growth conditions with an external initiator and a tailored initiator is then of minor importance. Thus, bis(tri-tert-butylphosphine)palladium(0) and a fifty-fold excess of bromobenzene were combined and allowed to react for 2.5 hours at $70^{\circ} \mathrm{C}$. Pentane was then added to precipitate the initiator complex. The whole reaction and the subsequent filtration have to be conducted under oxygen-free conditions to prevent any oxidation. ${ }^{67}$ Drying the crude yellow precipitate for several days under reduced pressure delivered the pure external initiator 4.

\section{Ring walking test}

The key aspect to why a controlled chain-growth polymerization with the $\mathrm{Pd}\left(\mathrm{P}^{\mathrm{t}} \mathrm{Bu} \mathrm{u}_{3}\right)$-protocol is achieved lies in the fact that the catalyst remains complexed to the $\pi$-conjugated system and is transferred to the terminal $\mathrm{C}-\mathrm{Br}$ bond after each reductive elimination. In order to test whether this is also the case for the phenanthrene-unit, one equivalent of 3,6-dibromo-9,10-di(octyloxy)phenanthrene 1 was reacted with one equivalent of phenyl boronic acid pinacol 5 in the presence of $5 \mathrm{~mol} \% \mathrm{Pd}\left(\mathrm{P}^{\mathrm{t}} \mathrm{Bu}_{3}\right)_{2}$ and $\mathrm{K}_{2} \mathrm{CO}_{3}$ in THF/water (Scheme 4). The crude mixture of this reaction was analyzed with ${ }^{1} \mathrm{H} N M R$ and mass spectroscopy (MS) to identify the obtained reaction products. An exclusive formation of the di-reacted product 6 was demonstrated based on the results provided in Figure 1 and Figures SI4-6. This demonstrates that, after the initial coupling reaction, the catalyst remains associated with the phenanthrene and is able to "walk" to the $\mathrm{C}-\mathrm{Br}$ at the 6-position. Therefore, the consecutive coupling reactions proceeds through an intramolecular transfer of the $\mathrm{Pd}\left(\mathrm{P}^{\mathrm{t}} \mathrm{Bu}_{3}\right)$ moiety over the phenanthrene unit. So far, we can anticipate that the polymerization of $\mathbf{3}$ will effectively follow a catalyst-transfer chain-growth polymerization mechanism.

\section{Suzuki-Miyaura coupling polymerization}

The polymerizations were initiated by adding the external initiator 4 ( $2.5 \mathrm{~mol} \%)$ in THF to 3 in a mixture of THF/water $(5 / 2,1.75 \mathrm{~mL})$ with $\mathrm{K}_{2} \mathrm{CO}_{3}(2 \mathrm{M})$. A first attempt at room temperature, overnight and using a monomer concentration of $5.25 \times 10^{-2} \mathrm{M}$ afforded polymers of which GPC spectra showed multiple shoulders and revealed large molar mass distributions. Visually it appeared that precipitation of the polymer occurred during the polymerization, probably because of the presence of water, a non-solvent. In order to overcome this problem, three possibilities could be envisaged: (i) decreasing the water content, (ii) decreasing the monomer concentration and (iii) increasing the temperature.

In order to introduce the lowest possible water content in the system, and based on the required use of $\mathrm{K}_{2} \mathrm{CO}_{3}, 2.0 \mathrm{mmol}$ of the base, i.e. $275 \mathrm{mg}$, were dissolved in the lowest water volume, $0.5 \mathrm{~mL}$. Further dilutions were then performed adding THF until precipitation. $0.25 \mathrm{~mL}$ water per millimol $\mathrm{K}_{2} \mathrm{CO}_{3}$ and a THF/water ratio of 20/1 proved to represent the smallest water content. This solvent ratio was used to perform several test experiments at different monomer concentrations. Since a modification of the monomer concentration comes along with an alteration of the reaction time, attention has been paid to keep the polymerization time within $120 \mathrm{~min}$. In this perspective, higher temperatures appear favorable but provide some side reactions which leads to broader molar mass distributions. Ideal conditions were set at ambient temperatures and an initial monomer concentration of $2.46 \times 10^{-2} \mathrm{M}$. Also polymerization 
reactions in the presence of CSF/18-crown-6 ether were tested, but revealed ineffective as no polymer was formed. ${ }^{9}$

\section{GPC analysis}

Despite all optimizations, the GPC chromatograms of the polymers showed shoulders at longer reaction times. To further develop our polymerization strategies, a more in-depth study of the underlying mechanism imposed itself. Two polymerizations, one with 2.5 mol\% initiator and the second with 5.0 mol\% initiator and both with polystyrene $\left(\overline{M_{p}}=317 \mathrm{~kg} / \mathrm{mol} ; \emptyset=1.02\right)$ as an internal reference, were monitored and analyzed with GPC to determine the $\overline{M_{n}}$ and $Ð$. Several GPC data were acquired during the polymerization reactions to follow the evolution of the reaction. After $50 \mathrm{~min}$, the GPC graph of the polymerization with 5.0 mol\% initiator clearly showed a unimodal curve with low $\bigoplus$ values (Figure 2, Table 3). After additional $10 \mathrm{~min}$ and according GPC analysis, the polymerization proceeds smoothly. The measured low polydispersity points to a fast initiation step. Unfortunately, low molar-mass tailing emerges starting from 75 min polymerization time. The small increase in $€$ present after 75 min indicates that side reactions are occurring. Moreover, a shoulder at higher molar masses appears in the spectrum after two hours reaction, which is likely to originate from disproportionation processes. A peak molecular mass $\left(\overline{M_{p}}\right)$ for the high molar mass tail of $13.4 \mathrm{~kg} / \mathrm{mol}$ in comparison of a $\overline{M_{p}}$ of $7.1 \mathrm{~kg} / \mathrm{mol}$ for the main peak supports this assumption.

The same behavior has been observed in GPC chromatograms of the polymerization with 2.5 mol\% initiator: a slow increase of the low $\oslash$ values during the polymerization and the appearance of a shoulder at lower molar mass starting from $75 \mathrm{~min}$ reaction time (Figure 2, Table 2). However, the higher molar-mass shoulder, observed with 5.0 mol\% initiator, is absent under the second conditions. The lower initiator concentration and consequently lower concentration of polymer chains render disproportionation less likely. Although higher molar masses, similar to the $5.0 \mathrm{~mol} \%$ initiator case, are expected because of the lower initiator/monomer ratio, the polymerization ends up with nearly the same $\overline{M_{n}}$ values. Clearly, whatever the initiator concentrations are, side reactions disturb the chain growth mechanism starting from $\sim 4.7 \mathrm{~kg} / \mathrm{mol}$ and $\overline{M_{n}}$ values are limited to $\sim 9.7 \mathrm{~kg} / \mathrm{mol}$. The unknown arising side reactions are therefore not dependent on the amount of initiator.

\section{MALDI-TOF}

In order to gain more insight in the nature of the side products, three samples of the polymerization with $2.5 \mathrm{~mol} \%$ initiator after $30 \mathrm{~min}, 50 \mathrm{~min}$ and $150 \mathrm{~min}$ reaction time were analyzed with MALDI-ToF mass spectrometry in order to define the end-groups. Figure 3 shows the spectrum recorded for the sample obtained after 30 min reaction. The peaks with the highest intensity correspond to polymer chains possessing a phenyl-group and a hydrogen $(\mathrm{Ph} / \mathrm{H})$ as end-groups. These polymers are correctly initiated by the external fenyl-initiator (4) and had a Pd-moiety at the end of the chain at the moment of termination. Indeed, quenching of the samples in a $2 \mathrm{M} \mathrm{HCl}$ in THF solution leads to the replacement of the Pd-moiety at the end of the chain by a hydrogen atom. The majority of the chains is thus correctly initiated and must then grow in a chain-growth manner after the initial 30 min reaction time. Nevertheless, also some polymer chains with a phenyl-group and a bromine atom $(\mathrm{Ph} / \mathrm{Br})$ were also produced according to the MALDI-ToF mass spectrum. These chains are also correctly initiated, but the $\mathrm{Pd}$-initiator was not connected to the polymer chain anymore prior to the quenching step, i.e. some undesired termination reaction had happened.

The released $\mathrm{Pd}$-catalyst can, in turn, oxidatively insert into an aryl-bromine bond of either a polymer without Pd-catalyst (=reinitiation) or either in unreacted monomer. This corresponds to a transfer

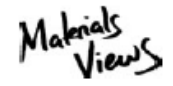


reaction, disrupting the controlled chain-growth nature of the polymerization. Such a process could explain the presence of chains end-capped with a boron-group and a hydrogen (Boron/H) or a bromine (Boron/Br) atom.

Afterwards, we compared the three samples with a peculiar attention to the $\mathrm{m} / \mathrm{z} 4300$ to 4560 (11 monomers) region of the mass spectra, see Figure 4. Over time, the proportion of the $\mathrm{Ph} / \mathrm{H}$-polymers (the growing polymer chains), diminishes in favor of $\mathrm{Ph} / \mathrm{Br}$-, Boron/ $\mathrm{H}$ - and Boron/Br-terminated chains because of the increasing degree of termination and transfer. In addition, the relative amount of the Boron/H-chains decreases again from $50 \mathrm{~min}$ to $150 \mathrm{~min}$ reaction time. At this point of the work, two explanations can be proposed to account for those observations. As for a first possibility, we can imagine that, together with the $\mathrm{Ph} / \mathrm{H}$-terminated chains, the Boron/H-chains are also converted to Boron/Br-chains. A second hypothesis relies on the occurrence of ring formation processes. Indeed, the signal at $m / z 4326$, that becomes increasingly important at prolonged reaction times, corresponds to a macrocycle species containing 10 monomer units. In the wider $\mathrm{m} / \mathrm{z}$ range presented in Figure 5 , ions corresponding to this macrocycle are also present for higher and lower numbers of monomer units, revealing the recurrent nature of those macromolecules. Lastly, we note that the mismatch between the molar masses found with GPC and MALDI-ToF is due to the inherent to the technique used. While GPC traditionally overestimates the molar masses of conjugated polymers because of the calibration against poly(styrene), MALDI-ToF underestimates the molar masses because of the easier ionization of the chains of lower molar mass.

From all our observations, we tentatively propose in Scheme 5 all the mechanisms involved in the polymerization of 3 . In the first stage of the 3,6-PPhs polymerization with $\mathrm{Pd}\left(\mathrm{P}^{\mathrm{t}} \mathrm{Bu}_{3}\right)$ as the catalyst, the polymerization follows a regular chain-growth mechanism. The external fenyl initiator 4 provides a proper initiation and the fenyl end-group is built in. Unfortunately, after a certain amount of catalytic cycles, the reductive elimination step is no longer followed by the intramolecular oxidative addition and the catalyst dissociates from the polymer chain, leaving a Br-end-capped polymer. This process is independent on the initiator concentration. The free catalyst can then insert in a monomer, resulting in polymer chains containing a boron-group instead of a fenyl group from the external initiator. Some of those chains terminate by dissociation of the Pd-catalyst (resulting in Boron/Br end-capped polymers), while others undergo cyclization.

\section{CONCLUSIONS}

We investigated the ability of poly(3,6-(9,10-di(octyloxy))phenantrene)s to be synthesized in a chaingrowth fashion with an external initiator. We attempted to apply the existing $\mathrm{Ni}$ - and Pd-based chaingrowth mechanisms. Those procedures which rely on a Grignard metathesis reaction were found inaccessible because of a very disappointing low yield when preparing the GRIM reagent. On the other 
hand, a Suzuki-Miyaura coupling polymerization with $A B$-equipped monomers and $P d\left(\mathrm{P}^{t} B u_{3}\right)$ as a catalyst allows polymerization. The reaction conditions were optimized and an in-depth study with GPC and MALDI-ToF of the underlying mechanisms was performed. Unfortunately, after a successful initiation, the chain-growth nature is maintained only at the beginning of the polymerization and transfer of the catalyst to the monomer happens slowly over time. The latter results in the formation of $\mathrm{AB}$-equipped polymers, which further leads to an intramolecular ring closure and therefore to the formation of macrocycles which affect the polymerization dramatically. A prolonged chain-growth mechanism can therefore not be demonstrated for the poly(3,6-(9,10-di(octyloxy))phenantrene)s.

\section{ACKNOWLEDGEMENTS}

M.V. thanks the Fund for Scientific Research (FWO-Vlaanderen) for a doctoral fellowship. We are also grateful to the Onderzoeksfonds KU Leuven/ Research Fund KU Leuven and the Air Force Office of Scientific Research. We acknowledge prof. T. Yokozawa for advice on the synthesis of the external phenyl-initiator. The Mons MS Laboratory acknowledges the 'Fonds de la Recherche Scientifique (FRSFNRS)' for its contribution to the acquisition of the Waters QToF Premier Mass Spectrometer. The present work is partially supported by the FRFC research program (convention No. 2.4508.12).

\section{REFERENCES AND NOTES}

(1) Lange, U.; Roznyatovskaya, N. V; Mirsky, V. M. Anal. Chim. Acta 2008, 614, 1-26.

(2) Vandewal, K.; Himmelberger, S.; Salleo, A. Macromolecules 2013, doi: 10.1021/ma400924b.

(3) Iovu, M. C.; Sheina, E. E.; Gil, R. R.; McCullough, R. D. Macromolecules 2005, 38, 8649-8656.

(4) Sheina, E. E.; Liu, J.; lovu, M. C.; Laird, D. W.; McCullough, R. D. Macromolecules 2004, 37, 35263528.

(5) Yokoyama, A.; Miyakoshi, R.; Yokozawa, T. Macromolecules 2004, 37, 1169-1171.

(6) Miyakoshi, R.; Yokoyama, A.; Yokozawa, T. J. Am. Chem. Soc. 2005, 127, 17542-17547.

(7) Verswyvel, M.; Verstappen, P.; De Cremer, L.; Verbiest, T.; Koeckelberghs, G. J. Polym. Sci., Part A: Polym. Chem. 2011, 49, 5339-5349.

(8) Willot, P.; Steverlynck, J.; Moerman, D.; Leclère, P.; Lazzaroni, R.; Koeckelberghs, G. Polym. Chem. 2013, 4, 2662-2671.

(9) Yokozawa, T.; Suzuki, R.; Nojima, M.; Ohta, Y.; Yokoyama, A. Macromol. Rapid Commun. 2011, 32, 801-806.

(10) Magurudeniya, H. D.; Sista, P.; Westbrook, J. K.; Ourso, T. E.; Nguyen, K.; Maher, M. C.; Alemseghed, M. G.; Biewer, M. C.; Stefan, M. C. Macromol. Rapid Commun. 2011, 32, 17481752.

(11) Bridges, C. R.; McCormick, T. M.; Gibson, G. L.; Hollinger, J.; Seferos, D. S. J. Am. Chem. Soc. 2013, doi: 10.1021/ja4073904.

(12) Bryan, Z. J.; Smith, M. L.; McNeil, A. J. Macromol. Rapid Commun. 2012, 33, 842-847.

(13) Sui, A.; Shi, X.; Wu, S.; Tian, H.; Geng, Y.; Wang, F. Macromolecules 2012, 45, 5436-5443.

(14) Yokoyama, A.; Suzuki, H.; Kubota, Y.; Ohuchi, K.; Higashimura, H.; Yokozawa, T. J. Am. Chem. Soc. 2007, 129, 7236-7237.

(15) Yokozawa, T.; Kohno, H.; Ohta, Y.; Yokoyama, A. Macromolecules 2010, 43, 7095-7100.

(16) Miyakoshi, R.; Shimono, K.; Yokoyama, A.; Yokozawa, T. J. Am. Chem. Soc. 2006, 128, 1601216013.

(17) Wu, S.; Bu, L.; Huang, L.; Yu, X.; Han, Y.; Geng, Y.; Wang, F. Polymer 2009, 50, 6245-6251.

(18) Kang, S.; Ono, R. J.; Bielawski, C. W. J. Am. Chem. Soc. 2013, 135, 4984-4987.

(19) Yokoyama, A.; Kato, A.; Miyakoshi, R.; Yokozawa, T. Macromolecules 2008, 41, 7271-7273.

(20) Khanduyeva, N.; Senkovskyy, V.; Beryozkina, T.; Horecha, M.; Stamm, M.; Uhrich, C.; Riede, M.; Leo, K.; Kiriy, A. J. Am. Chem. Soc. 2009, 131, 153-161. 
(21) Bronstein, H. A.; Luscombe, C. K. J. Am. Chem. Soc. 2009, 131, 12894-12895.

(22) Smeets, A.; Van den Bergh, K.; De Winter, J.; Gerbaux, P.; Verbiest, T.; Koeckelberghs, G. Macromolecules 2009, 42, 7638-7641.

(23) Kempf, C. N.; Smith, K. A.; Pesek, S. L.; Li, X.; Verduzco, R. Polym. Chem. 2013, 4, 2158-2163.

(24) Kochemba, W. M.; Pickel, D. L.; Sumpter, B. G.; Chen, J.; Kilbey, S. M. Chem. Mater. 2012, 24, 4459-4467.

(25) Smeets, A.; Willot, P.; De Winter, J.; Gerbaux, P.; Verbiest, T.; Koeckelberghs, G. Macromolecules 2011, 44, 6017-6025.

(26) Kim, H.-J.; Lee, Y. J.; Hwang, S. S.; Choi, D. H.; Yang, H.; Baek, K.-Y. J. Polym. Sci., Part A: Polym. Chem. 2011, 4221-4226.

(27) Senkovskyy, V.; Beryozkina, T.; Bocharova, V.; Tkachov, R.; Komber, H.; Lederer, A.; Stamm, M.; Severin, N.; Rabe, J. P.; Kiriy, A. Macromol. Symp. 2010, 291-292, 17-25.

(28) Wang, F.; Rauh, R. D.; Rose, T. L. J. Am. Chem. Soc. 1997, 119, 11106-11107.

(29) Bras, J.; Guillerez, S.; Pépin-Donat, B. Chem. Mater. 2000, 12, 2372-2384.

(30) Yuan, M.; Okamoto, K.; Bronstein, H. A.; Luscombe, C. K. ACS Macro Lett. 2012, 1, 392-395.

(31) Okamoto, K.; Housekeeper, J. B.; Michael, F. E.; Luscombe, C. K. Polym. Chem. 2013, 4, 34993506.

(32) Tomalia, D. A.; Fréchet, J. M. J. J. Polym. Sci., Part A: Polym. Chem. 2002, 40, 2719-2728.

(33) Gao, C.; Yan, D. Prog. Polym. Sci. 2004, 29, 183-275.

(34) Fréchet, J. M. J. J. Polym. Sci., Part A: Polym. Chem. 2003, 41, 3713-3725.

(35) Astruc, D.; Boisselier, E.; Ornelas, C. Chem. Rev. 2010, 110, 1857-1959.

(36) Harpham, M. R.; Süzer, O.; Ma, C.-Q.; Bäuerle, P.; Goodson, T. J. Am. Chem. Soc. 2009, 131, 973979.

(37) Taerum, T.; Lukoyanova, O.; Wylie, R. G.; Perepichka, D. F. Org. Lett. 2009, 11, 3230-3233.

(38) Nicolas, Y.; Blanchard, P.; Levillain, E.; Allain, M.; Mercier, N.; Roncali, J. Org. Lett. 2004, 6, 273276.

(39) Xia, C.; Fan, X.; Locklin, J.; Advincula, R. C.; Gies, A.; Nonidez, W. J. Am. Chem. Soc. 2004, 126, 8735-8743.

(40) Xu, M.-H.; Pu, L. Tetrahedron Lett. 2002, 43, 6347-6350.

(41) Segawa, Y.; Higashihara, T.; Ueda, M. Polym. Chem. 2013, 4, 1208-1215.

(42) Akagi, K. Science 1998, 282, 1683-1686.

(43) Nelson, J. C. Science 1997, 277, 1793-1796.

(44) Prince, R. B.; Saven, J. G.; Wolynes, P. G.; Moore, J. S. J. Am. Chem. Soc. 1999, 121, 3114-3121.

(45) Prest, P.-J.; Prince, R. B.; Moore, J. S. J. Am. Chem. Soc. 1999, 121, 5933-5939.

(46) Goto, H.; Okamoto, Y.; Yashima, E. Chem. Eur. J. 2002, 8, 4027-4036.

(47) Vanormelingen, W.; Van den Bergh, K.; Verbiest, T.; Koeckelberghs, G. Macromolecules 2008, 41, 5582-5589.

(48) Kim, H.-J.; Lim, Y.-B.; Lee, M. J. Polym. Sci., Part A: Polym. Chem. 2008, 46, 1925-1935.

(49) Nakano, T.; Okamoto, Y. Chem. Rev. 2001, 101, 4013-4038.

(50) Verswyvel, M.; Koeckelberghs, G. Polym. Chem. 2012, 3, 3203-3216.

(51) Cornelissen, J. J.; Rowan, a E.; Nolte, R. J.; Sommerdijk, N. a Chem. Rev. 2001, 101, 4039-4070.

(52) Ho, R.-M.; Chiang, Y.-W.; Lin, S.-C.; Chen, C.-K. Prog. Polym. Sci. 2011, 36, 376-453.

(53) Schmuck, C. Angew. Chem. Int. Ed. 2003, 42, 2448-2452.

(54) Vanormelingen, W.; Smeets, A.; Franz, E.; Asselberghs, I.; Clays, K.; Verbiest, T.; Koeckelberghs, G. Macromolecules 2009, 42, 4282-4287.

(55) Suh, H.; Jin, Y.; Park, S. H.; Kim, D.; Kim, J.; Kim, C.; Kim, J. Y.; Lee, K. Macromolecules 2005, 38, 6285-6289.

(56) Grem, G.; Leditzky, G.; Ullrich, B.; Leising, G. Adv. Mater. 1992, 4, 36-37. 
(57) Yang, Y.; Pei, Q.; Heeger, A. J. Synth. Met. 1996, 78, 263-267.

(58) Balanda, P. B.; Ramey, M. B.; Reynolds, J. R. Macromolecules 1999, 32, 3970-3978.

(59) Fukuda, M.; Sawada, K.; Yoshino, K. J. Polym. Sci., Part A: Polym. Chem. 1993, 31, 2465-2471.

(60) Pei, Q.; Yang, Y. J. Am. Chem. Soc. 1996, 118, 7416-7417.

(61) Scherf, U.; List, E. J. W. Adv. Mater. 2002, 14, 477-487.

(62) De Winter, J.; Deshayes, G.; Boon, F.; Coulembier, O.; Dubois, P.; Gerbaux, P. J Mass Spectrom 2011, 46, 237-246.

(63) Bhatt, M. V. Tetrahedron 1964, 20, 803-821.

(64) Li, J.; Hu, G.; Wang, N.; Hu, T.; Wen, Q.; Lu, P.; Wang, Y. J. Org. Chem. 2013, 78, 3001-3008.

(65) Very recently, Fuji et al. reported a Marahashi coupling polymeriation with lithiated monomers and Ni(NHC). Fuji, K.; Tamba, S.; Shono, K.; Sugie, A.; Mori, A. J. Am. Chem. Soc. 2013, doi: 10.1021/ja406374t.

(66) Huddleston, N. E.; Sontag, S. K.; Bilbrey, J. A.; Sheppard, G. R.; Locklin, J. Macromol. Rapid Commun. 2012, 33, 2115-2120.

(67) Stambuli, J. P.; Incarvito, C. D.; Bühl, M.; Hartwig, J. F. J. Am. Chem. Soc. 2004, 126, 1184-1194. 


\section{CAPTIONS TO FIGURES AND SCHEMES}

SCHEME 1 Existing chain-growth polymerization mechanisms for conjugated polymers.

SCHEME 2 Synthesis of the monomer $\mathbf{3}$ used in the Suzuki-Miyaura polymerization.

SCHEME 3 Synthesis of the initiator 4 used in the Suzuki-Miyaura polymerization.

SCHEME 4 Ring walking test of phenanthrene 1 during the Suzuki-Miyaura coupling with $\mathbf{5}$.

SCHEME 5 Schematic representation of the 3,6-PPhs polymerization and the occurring side reactions with $\mathrm{Pd}\left(\mathrm{P}^{\mathrm{t}} \mathrm{Bu}_{3}\right)$ as a catalyst. The bold codes under the polymers correspond to the used annotations in MALDI-Tof spectra in Figures 3-5.

FIGURE 1 Aromatic region of the ${ }^{1} \mathrm{H}$ NMR spectrum of the crude mixture resulting from the ring walking test of 1 and 5 with $\mathrm{Pd}\left(\mathrm{P}^{\mathrm{t}} \mathrm{Bu}_{3}\right)_{2}$. The full ${ }^{1} \mathrm{H}$ NMR spectrum and $\mathrm{MS}$ analysis can be found in the Supporting Information (Figure $\mathrm{SI} 3$ ).

FIGURE 2 Molar mass vs. conversion plots for 3,6-PPhs with (A) 2.5 mol\% and (B) 5.0 mol\% $\mathrm{Pd}\left(\mathrm{P}^{\mathrm{t}} \mathrm{Bu} \mathrm{u}_{3}\right)$ initiator (c= $2.46 \times 10^{-2} \mathrm{M}$ in THF/ $\mathrm{H}_{2} \mathrm{O}$ ). The signal at $540 \mathrm{~s}$ originates from the THF stabilizator ( $\mathrm{BHT}$ ).

FIGURE 3 MALDI-ToF spectrum of 3,6-PPhs after 30 min reaction time with $2.5 \mathrm{~mol} \% \mathrm{Pd}\left(\mathrm{P}^{\mathrm{t}} \mathrm{Bu}_{3}\right)$ initiator $(\mathrm{c}=2.46 \times$ $10^{-2} \mathrm{M}$ in THF/ $\mathrm{H}_{2} \mathrm{O}$ ).

FIGURE 4 MALDI-ToF spectra of 3,6-PPhs for the region $\mathrm{m} / \mathrm{z} 4270$ to 4620 after (A) $30 \mathrm{~min}$, (B) $50 \mathrm{~min}$ and (C) 150 min reaction time with $2.5 \mathrm{~mol} \% \mathrm{Pd}\left(\mathrm{P}^{\mathrm{t}} \mathrm{Bu} \mathrm{u}_{3}\right)$ initiator $\left(\mathrm{c}=2.46 \times 10^{-2} \mathrm{M}\right.$ in $\left.\mathrm{THF} / \mathrm{H}_{2} \mathrm{O}\right)$. A wider view can be found in the Supporting Information (Figure SI15).

FIGURE 5 MALDI-ToF spectra of 3,6-PPhs for the region $\mathrm{m} / \mathrm{z} 2590$ to 4510 after (A) 50 min and (B) 150 min reaction time with $2.5 \mathrm{~mol} \% \mathrm{Pd}\left(\mathrm{P}^{\mathrm{t}} \mathrm{Bu}_{3}\right)$ initiator $\left(\mathrm{c}=2.46 \times 10^{-2} \mathrm{M}\right.$ in THF/ $\left.\mathrm{H}_{2} \mathrm{O}\right)$. A wider view can be found in the Supporting Information (Figure SI16). 


\section{GRAPHICAL ABSTRACT}

Michiel Verswyvel, Charly Hoebers, Julien De Winter, Pascal Gerbaux and Guy Koeckelberghs

\section{Study of the controlled chain-growth polymerization of poly(3,6-phenanthrene)}

The possibility to prepare poly(3,6-(9,10-di(octyloxy))phenanthrene)s in a chain-growth fashion is investigated. Different polymerization protocols were tested and $\mathrm{Pd}\left(\mathrm{P}^{t} \mathrm{Bu}_{3}\right)$ was found to perform the best. A GPC and MALDI-ToF study revealed transfer reactions and the formation of macrocyclic rings.

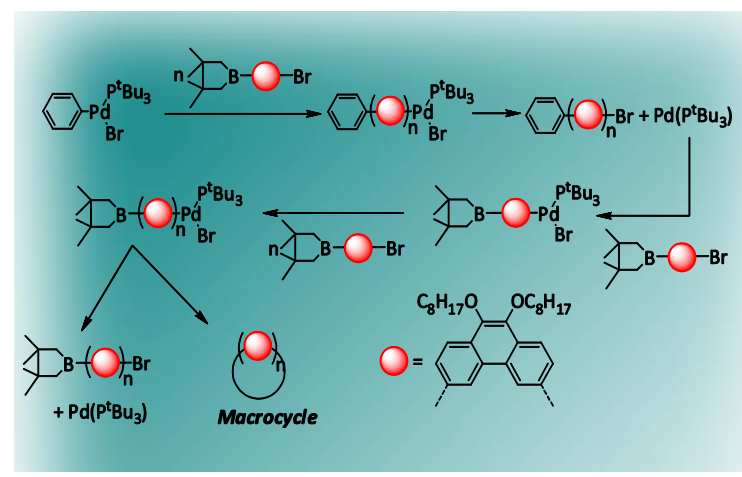

